\title{
Nitrate reduction and the isolation of Nit- mutants in Hansenula polymorpha
}

\author{
Cristina Pignocchi, Enrico Berardi and Brian S. Cox
}

Laboratorio di Genetica Microbica, Dipartimento di Biotecnologie Agrarie ed Ambientali, Università degli Studi di Ancona, Via Brecce Bianche, 1-60131 Ancona, Italy
Author for correspondence: Enrico Berardi. Tel: +39 71 2204922. Fax: +39 712204858. e-mail : berardi@popcsi.unian.it

\begin{abstract}
Hansenula polymorpha (syn. Pichia angusta) is able to grow on nitrate as sole nitrogen source. Nitrate reductase (NR) assays, optimized in crude extracts from nitrate-grown cells, revealed that NR preferentially used NADPH, but also used NADH, as electron donor and required FAD for maximum activity. NR activity was present in nitrate-grown and nitrite-grown cells, and was absent in cells grown in ammonium, glutamate and methylamine. Addition of reduced nitrogen compounds to nitrate-grown cells led to loss of NR activity, even if added with nitrate. Under nitrogen starvation, NR activity was not observed; however, following growth on nitrate, NR activity is maintained in the absence of nitrate. Increases but not decreases in NR activity were dependent on protein synthesis. Conditions for chlorate selection were optimized, and Nit(nitrate-) mutants were isolated. Some of these mutants showed reduced or absent NR activity. Sixty-one $N^{-}$mutants revealed the monogenic recessive nature of their lesions and were grouped in 10 complementation classes. These mutants will be used in gene cloning experiments aimed at identifying structural and regulatory elements involved in the first step of nitrate reduction.
\end{abstract}

Keywords: nitrate assimilation, nitrate reductase, $\mathrm{Nit}^{-}$mutants, chlorate resistance, Hansenula polymorpha

\section{INTRODUCTION}

In the biosphere, nitrate assimilation is the major pathway converting inorganic nitrogen to organic forms. It has been estimated that more than $2 \times 10^{4}$ megatons of organic nitrogen per year are produced by nitrate assimilation in a variety of organisms, including bacteria, fungi, algae and plants (Guerrero et al., 1981). As pointed out by Solomonson \& Barber (1990), as much as $25 \%$ of the energy of photosynthesis is consumed in driving nitrate assimilation. Therefore, interest in the nitrate assimilation pathway has been steadily growing, especially in relation to crop yield improvements and to the worldwide concern over the use of nitrate fertilizers, costly in terms of production and in terms of ecological and toxicological impact.

Nitrate assimilation consists of a two-step reduction of nitrate to ammonia, catalysed by the sequential action of nitrate reductase (NR) and nitrite reductase (NiR). NR catalyses the two-electron reduction of nitrate to nitrite; it is a complex multicentre enzyme that in eukaryotes

Abbreviations: NiR, nitrite reductase; NR, nitrate reductase. uses $\mathrm{NAD}(\mathrm{P}) \mathrm{H}$ as electron donor and contains $\mathrm{FAD}$, ferrohaem and molybdopterin prosthetic groups. It is considered to be a limiting factor for growth, development and protein production in all nitrate-assimilating organisms. NiR catalyses the six-electron reduction of nitrite to ammonia ; it is also a multicentre enzyme that in plants uses reduced ferredoxin as electron donor, whilst in bacteria and fungi uses $\mathrm{NAD}(\mathrm{P}) \mathrm{H}$ (Campbell \& Kinghorn, 1990, and references therein).

The genetics and molecular biology of nitrate assimilation have been studied mostly in plants, filamentous fungi and bacteria (Wray \& Kinghorn, 1989, and reviews therein). Despite being considerably advantageous as experimental models, yeasts have been neglected in these studies, perhaps, as noted by Hipkin (1989), because of the tendency to equate yeast with Saccharomyces cerevisiae, a species unable to assimilate nitrate or nitrite. However, a large number of nitrate-assimilating yeasts exist (Barnett et al., 1984), and various investigations have shown that the enzymological layout of their nitrate metabolism is similar to that of the other nitrate-assimilating eukaryotes (Hipkin, 1989, and references therein). The yeast Hansenula polymorpha 
(syn. Pichia angusta) promises well as a model for studying nitrate assimilation, since it is amenable to genetic analysis, transformation and chromosome engineering (vide Berardi, 1997). This ascomycete has long served as a model to study peroxisome function (Veenhuis, 1992; Waterham \& Cregg, 1997) and more recently is being employed for heterologous protein expression (e.g. Berardi, 1997; Faber et al., 1996). To understand the nitrate assimilation of $H$. polymorpha it is important to identify and characterize genetic factors involved in this process. As yet, the screening and isolation of nitrate assimilation mutants in this yeast have not been attempted, although the isolation of genes involved in this metabolism has been reported (Avila et al., 1995; Brito et al., 1996; Pérez et al., 1997). Here we describe the isolation and characterization of 10 complementation groups of $H$. polymorpha mutants with reduced or undetectable NR activities. It is likely that these mutants identify structural and regulatory elements involved in the first step of nitrate reduction.

\section{METHODS}

Strains. All are derivatives of Hansenula polymorpha homothallic haploid NCYC 495. M6 (met6-1) and L1 (leu1-1) are Nit (nitrate) ${ }^{+}$strains used as 'control' strains. M6 was used to isolate all $\mathrm{Nit}^{-}$mutants; $\mathrm{L} 1$ served to obtain all nit $/$ nit diploids.

Media. YPD contained $2 \%$ glucose, $1 \%$ yeast extract and $2 \%$ peptone. ME contained $2 \%$ malt extract. All the following minimal media contained $2 \%$ glucose, $0.2 \%$ yeast nitrogen base without amino acids and ammonium sulphate (Difco); when necessary, $0.006 \%$ leucine or $0.002 \%$ methionine was added. In addition, MA1 contained $38 \mathrm{mM}$ ammonium sulphate, MA2 contained $50 \mathrm{mM}$ ammonium chloride, MC contained $1.8 \mathrm{mM}$ sodium nitrite $+0.3-0.8 \mathrm{M}$ potassium chlorate, MN contained $50 \mathrm{mM}$ sodium nitrate, MN1 contained $8 \mathrm{mM}$ potassium nitrate, MN2 contained $25-200 \mathrm{mM}$ sodium nitrate, $\mathrm{MN} 3$ contained $1.8 \mathrm{mM}$ sodium nitrite, $\mathrm{MG}$ contained $4 \mathrm{mM}$ sodium glutamate, MMa contained $10 \mathrm{mM}$ methylamine, $\mathrm{MH}$ contained $0.7 \mathrm{mM}$ hypoxanthine, MAs contained $4 \mathrm{mM}$ aspartate and MMo contained $50 \mathrm{mM}$ sodium nitrate $+200 \mathrm{mM}$ sodium molybdate. When necessary, $1.6 \%$ agar was added.

Induction and repression experiments. All cultures were grown in $250 \mathrm{ml}$ flasks with $100 \mathrm{ml}$ medium, using an orbital incubator at $37^{\circ} \mathrm{C}$ and 220 r.p.m. After $15 \mathrm{~h}$ pre-cultivations in YPD, $5 \times 10^{5} \mathrm{M} 6$ or $\mathrm{Nit}^{-}$mutants $\mathrm{ml}^{-1}$ were washed and inoculated in MG flasks (induction experiments) or MN2 flasks (repression experiments). After $15 \mathrm{~h}$ cultivation (lateexponential phase), a different nitrogen source (or combinations of sources) was added (nitrite, $1 \mathrm{mM}$ or $10 \mathrm{mM}$; methylamine, $10 \mathrm{mM}$; others, $50 \mathrm{mM}$ ); when necessary, $100 \mathrm{mg}$ cycloheximide $\mathrm{mg}^{-1}$ was also added. One of the flasks received no nitrogen addition ('negative control'). Cell number (direct count) and NR activities were determined at fixed intervals.

NR assays. Extraction buffer $(100 \mathrm{mM}$ potassium phosphate buffer, $\mathrm{pH} 7 \cdot 4 ; 20 \mu \mathrm{M}$ FAD; $1 \mathrm{mM}$ EDTA; $1 \mathrm{mM}$ PMSF) and reaction mixture (see below) were after González \& Siverio (1992). Crude extracts were obtained by glass bead vortexing in extraction buffer. Protein concentrations were determined using a Bio-Rad kit (catalogue no. 500-0006; BSA as standard).
$\mathrm{NAD}(\mathrm{P}) \mathrm{H}: \mathrm{NR}(\mathrm{EC} 1.6 .6 .2)$ activities of crude extracts were assayed spectrophotometrically ( $340 \mathrm{~nm}$; Varian 'Cary 3' spectrophotometer) by monitoring the nitrate-dependent $\mathrm{NAD}(\mathrm{P}) \mathrm{H}$ oxidation in reaction mixtures containing crude extract $(0 \cdot 10-0 \cdot 15 \mathrm{mg}$ protein), $100 \mathrm{mM}$ potassium phosphate buffer, $\mathrm{pH} 7 \cdot 4,1 \mathrm{mM}$ PMSF, $10 \mathrm{mM}$ potassium metabisulphite, $0.2 \mathrm{mM} \mathrm{NAD}(\mathrm{P}) \mathrm{H}$ and $20 \mathrm{mM}$ sodium nitrate. The plots of $\mathrm{NAD}(\mathrm{P}) \mathrm{H}$ absorbance against time were linear for a few minutes. Unless otherwise specified, the assay temperature was $37^{\circ} \mathrm{C}$. The difference between the rate of $\operatorname{NAD}(\mathrm{P}) \mathrm{H}$ oxidation in the presence and absence of nitrate was used to calculate the NR activity. Specific activities are expressed as nmol $\mathrm{NAD}(\mathrm{P}) \mathrm{H}$ oxidized $\mathrm{min}^{-1}$ (mg protein) ${ }^{-1}$.

Mutant isolation. Chlorate-resistant $\left(\mathrm{Clo}^{\mathrm{r}}\right)$ mutants were obtained by positive selection on MC plates (no mutagens used; $10^{7} \mathrm{M} 6$ cells per plate; $37^{\circ} \mathrm{C}$ for $15 \mathrm{~d}$ ). To isolate $\mathrm{Nit}^{-}$ mutants, $\mathrm{Clo}^{\mathrm{r}}$ mutants were purified, replica-plated onto MA1, MN and MN3 plates, incubated for 2-4d and then grouped according to their growth on these media. To isolate $\mathrm{NR}^{-}$mutants, all Nit ${ }^{-}$mutants that failed to grow on nitrate plates but retained growth on nitrite were cultivated in YPD flasks, washed and inoculated $\left(10^{6}\right)$ in MA2 flasks. After $15 \mathrm{~h}$ incubation, the cells were washed, transferred to MN2 flasks for $3 \mathrm{~h}$ and then subjected to NR assays.

Crosses and sporulations. These were done onto ME plates, as described by Gleeson \& Sudbery (1988).

\section{RESULTS}

\section{Assay conditions and electron donor}

After optimizing the NR assay conditions in crude extracts of nitrate-grown M6 cells, we were able to obtain a quick and sensitive assay based on the measurement of the initial rate of $\mathrm{NAD}(\mathrm{P}) \mathrm{H}$ oxidation associated with the enzymic nitrate reduction. We would like to point out that our continuous monitoring assay allows one to verify the linearity of $\mathrm{NAD}(\mathrm{P}) \mathrm{H}$ concentration against time, and is therefore very accurate. Kinetic methods to measure NR activity in yeasts are not new : Bruinenberg et al. (1983) described a spectrophotometric assay for Candida utilis. However, all our attempts to reproduce this assay with $H$. polymorpha strains were unsuccessful. We found that the NR of $H$. polymorpha is bispecific, i.e. uses both NADPH and $\mathrm{NADH}$ as electron donors $[\mathrm{NAD}(\mathrm{P}) \mathrm{H}: \mathrm{NR} ; 1$ 1.6.6.2]. However, NADPH was more effective than NADH as electron donor: after $3 \mathrm{~h}$ cultivation, the NADPHdependent NR activity is approximately threefold higher than the NADH-dependent activity. Potassium metabisulphite, a NiR inhibitor, was essential. Adding FAD and PMSF (a protease inhibitor) to the extraction buffer resulted in higher activities (approx. twofold), suggesting a stabilizing role of these compounds during extraction and storage. NADPH:NR activities were also studied as a function of the reaction temperature. Maximal activities are observed around $40^{\circ} \mathrm{C}$, which is consistent with the optimal growth temperature of $H$. polymorpha $\left(40-42^{\circ} \mathrm{C}\right)$. In the interval $35-45^{\circ} \mathrm{C}$, the activities are nearly maximal $(>95 \%)$, whereas at 30 and $50{ }^{\circ} \mathrm{C}$ the activities are lower than $85 \%$ of maximum. Since NR stability in the extracts may vary with the temperature, these observations are just indicative. 


\section{Growth on different nitrogen sources}

$H$. polymorpha was able to grow on media with all the nitrogen sources tested, i.e. ammonium, nitrate, nitrite, glutamate, aspartate, methylamine and hypoxanthine. The exponential growth rates on all the sources were similar, with the exception of nitrite, which appeared to be a poor nitrogen source (data not shown). After precultivation in minimal ammonium medium (MA), significant lag phases were only observed on nitrite (approx. $7 \mathrm{~h}$ ), nitrate (approx. $1 \mathrm{~h}$ ) and methylamine (approx. $2 \mathrm{~h}$ ).

\section{Appearance of the NR activity}

Preliminary experiments on cells harvested during the late-exponential phase of growth demonstrated high NR activities on nitrate media, low NR activities on nitrite media and no activities on all other media (data not shown), suggesting that, as in other organisms, the nitrate metabolism of $H$. polymorpha is an inducible system responding mainly to nitrate. Time-course NR measurements of cells transferred to nitrate media after ammonium or glutamate pre-cultivation revealed progressive increases of NR activities after nitrate was made available (Fig. 1a). Increasing the nitrate concentration in the medium led to significant depressions of the induction kinetics and of the maximum NR activity (Fig. 1b). During these experiments, the growth of the cell population was shown to be equal to $0 \cdot 1 \Delta \mathrm{OD} \mathrm{h}^{-1}$ (25 mM flasks) or $0.05 \Delta \mathrm{OD} \mathrm{h}^{-1}$ (all other flasks). The appearance of NR activity in response to nitrate is suppressed by cycloheximide (Fig. 1b).

To study the effect of nitrate on NR induction, we set up various flask cultures using glutamate, an NR-noninducing nitrogen source. During the late-exponential phase of growth, when the residual glutamate in the medium was approaching exhaustion, the desired nitrogen sources were added and the NR activities were then measured at fixed intervals. The results, summarized in Fig. 1(a), revealed that nitrate in combination with glutamate or nitrite retains a very weak inducing effect, whereas in combination with ammonium or methylamine it loses its inducing effect. During these experiments, the growth of the cell population was shown to be equal to $0.5 \Delta \mathrm{OD} \mathrm{h}{ }^{-1}$ (ammonium + nitrate and glutamate + nitrate) or 0.4 $\Delta \mathrm{OD} \mathrm{h}^{-1}$ (methylamine + nitrate) or $0.02 \Delta \mathrm{OD} \mathrm{h}^{-1}$ (nitrite + nitrate). Similar experiments with no nitrogen additions revealed that nitrogen-starved cells after growth on ammonium or glutamate did not contain measurable NR activities during the time considered (not shown).

\section{Disappearance of the NR activity}

We also investigated the effect that various repressing nitrogen sources, alone or in combination with nitrate, exerted over NR activity. $H$. polymorpha was grown in nitrate medium (MN2) until late-exponential phase,
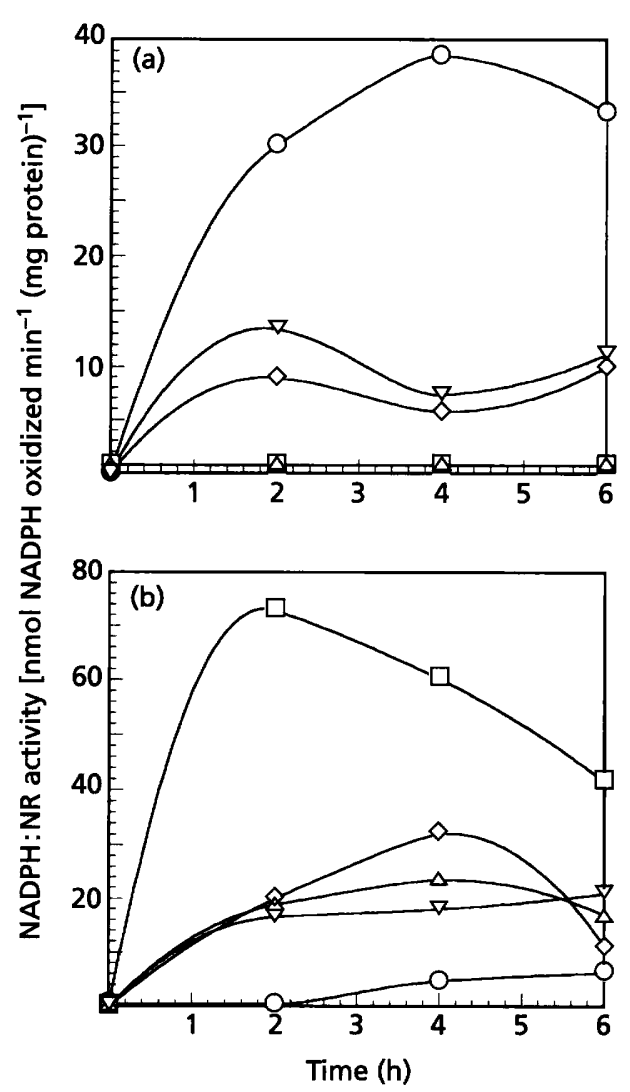

Fig. 1. (a) Effect of the addition of different nitrogen sources on the NADPH: NR activity of crude extracts of $H$. polymorpha M6 pre-grown with $4 \mathrm{mM}$ glutamate as sole nitrogen source. Nitrate $(50 \mathrm{mM})+$ another nitrogen source were added in the late-exponential phase (zero time); $0,50 \mathrm{mM}$ nitrate; $\nabla$, $50 \mathrm{mM}$ nitrate + $1.9 \mathrm{mM}$ nitrite; $\triangle, 50 \mathrm{mM}$ nitrate $+37 \mathrm{mM}$ methylamine; $\square, 50 \mathrm{mM}$ nitrate $+50 \mathrm{mM}$ ammonium; $\diamond$, $50 \mathrm{mM}$ nitrate $+50 \mathrm{mM}$ glutamate. The experiments were done in triplicate without significant differences. (b) Appearance of NADPH:NR activity in response to the addition of nitrate, alone or with cycloheximide, at different concentrations in crude extracts of $H$. polymorpha $\mathrm{M} 6$ pre-grown with $4 \mathrm{mM}$ glutamate as sole nitrogen source. Nitrate was added in the lateexponential phase; $\square, 25 \mathrm{mM}$ nitrate; $\diamond, 50 \mathrm{mM}$ nitrate; $\triangle$, $100 \mathrm{mM}$ nitrate; $\nabla, 200 \mathrm{mM}$ nitrate; $0,50 \mathrm{mM}$ nitrate $+100 \mu \mathrm{g}$ cycloheximide $\mathrm{ml}^{-1}$. The experiments were done in triplicate without significant differences; a similar pattern was obtained with ammonium pre-cultivation.

when the residual nitrate in the medium was approaching exhaustion and the NR activities were around $10 \mathrm{nmol} \mathrm{min}^{-1}$ (mg protein) $)^{-1}$. After adding the various nitrogen compounds, we measured the NR activities at fixed intervals. The results showed that adding nitrate alone leads to significant increases of NR activities (approx. threefold in $6 \mathrm{~h}$ ), whilst adding nitrite (alone or with nitrate) causes a growth arrest or a long lag phase, probably due to toxic effect, followed by a slow induction of NR up to $15-20 \mathrm{nmol} \mathrm{m^{-1 }}$ (mg protein) ${ }^{-1}$. All other nitrogen sources, even in combination with nitrate, trigger a loss of NR activities. However, in the presence of glutamate + nitrate, this loss is preceded by a small increase of NR activity (approx. twofold in $2 \mathrm{~h}$ ). 
Table 1. Complementation matrix representing $20 \mathrm{Nit}^{-}$mutants of $H$. polymorpha crossed in all pairwise combinations

+ , Crosses which grow on nitrate medium, indicating complementation; - , crosses which do not grow on nitrate medium, indicating non-complementation. NADPH:NR activities of control strain (M6) and of the $20 \mathrm{Nit}^{-}$mutants are also reported (last column).

\begin{tabular}{|c|c|c|c|c|c|c|c|c|c|c|c|c|c|c|c|c|c|c|c|c|c|}
\hline & CP1 & CP2 & $\mathrm{CP} 3$ & CP4 & CP5 & CP6 & $\mathrm{CP} 7$ & CP8 & $\mathrm{CP} 9$ & CP10 & CP11 & CP12 & CP13 & CP14 & CP15 & CP16 & CP192 & $\mathrm{CP} 193$ & CP221 & CP222 & Activity \\
\hline $\mathrm{CP} 1$ & - & + & + & - & + & + & + & + & + & + & - & - & - & + & + & + & + & + & - & + & 3.5 \\
\hline CP2 & & - & + & + & + & + & + & + & + & + & + & + & + & + & + & - & + & + & + & - & $2 \cdot 0$ \\
\hline $\mathrm{CP} 3$ & & & - & + & + & + & + & + & + & + & + & + & + & + & + & + & + & + & + & + & 3.7 \\
\hline CP4 & & & & - & + & + & + & + & + & + & - & - & - & + & + & + & + & + & - & + & ND \\
\hline CP5 & & & & & - & - & + & - & + & + & + & + & + & + & - & + & + & + & + & + & ND \\
\hline CP6 & & & & & & - & + & - & + & + & + & + & + & + & - & + & + & + & + & + & ND \\
\hline CP7 & & & & & & & - & + & + & + & + & + & + & + & + & + & + & + & + & + & ND \\
\hline CP8 & & & & & & & & - & + & + & + & + & + & + & - & + & + & + & + & + & ND \\
\hline $\mathrm{CP} 9$ & & & & & & & & & - & + & + & + & + & + & + & + & + & + & + & + & $2 \cdot 8$ \\
\hline CP10 & & & & & & & & & & - & + & + & + & + & + & + & + & + & + & + & ND \\
\hline CP11 & & & & & & & & & & & - & - & - & + & + & + & + & + & - & + & ND \\
\hline CP12 & & & & & & & & & & & & - & - & + & + & + & + & + & - & + & ND \\
\hline CP13 & & & & & & & & & & & & & - & + & + & + & + & + & - & + & ND \\
\hline CP14 & & & & & & & & & & & & & & - & + & + & + & + & + & + & ND \\
\hline CP15 & & & & & & & & & & & & & & & - & + & + & + & + & + & ND \\
\hline CP16 & & & & & & & & & & & & & & & & - & + & + & + & - & ND \\
\hline CP192 & & & & & & & & & & & & & & & & & - & + & + & + & ND \\
\hline CP193 & & & & & & & & & & & & & & & & & & - & + & + & ND \\
\hline CP221 & & & & & & & & & & & & & & & & & & & - & + & ND \\
\hline CP222 & & & & & & & & & & & & & & & & & & & & - & ND \\
\hline M6 & & & & & & & & & & & & & & & & & & & & & $27 \cdot 0$ \\
\hline
\end{tabular}

*NADPH:NR activity was determined in crude extracts of these strains grown in ammonium medium for $15 \mathrm{~h}$, washed, transferred to nitrate medium for $3 \mathrm{~h}$ and then subjected to NR assays. The results are expressed as nmol NADPH oxidized min ${ }^{-1}$ (mg protein) ${ }^{-1}$; $\mathrm{ND}$ not detected. The experiments were done in triplicate without significant differences.

In general, the observed losses are more rapid with ammonium than with glutamate or methylamine. Interestingly, these losses of activities are also observed if cycloheximide is added. If no nitrogen compounds were added, under the interval of time considered no significant losses of the initial NR activity were observed, unless cycloheximide was added.

\section{Isolation of $\mathrm{Clo}^{\mathrm{r}}$ mutants}

According to the principles described by Åberg (1947), if NR is expressed on chlorate plates, toxicity phenomena may impede cell growth (see also Cove, 1976). Mutants with reduced NR activities can survive, as long as a suitable nitrogen source is supplied. Therefore, it is crucial that this nitrogen source could allow NR expression. As previously described, nitrite allows measurable NR activities. In preliminary experiments, we established that the optimal nitrite concentration for growth on plates of $H$. polymorpha M6 is $1.8 \mathrm{mM}$. On nitrite medium with $0.3-0.8 \mathrm{M}$ chlorate, $H$. polymorpha M6 showed no growth (chlorate-sensitive; $\mathrm{Clo}^{\mathrm{s}}$ ). Therefore, we selected $\mathrm{Clo}^{\mathrm{r}}$ mutants on this medium. After $15 \mathrm{~d}$ incubation, several dozen colonies were obtained on each plate, their numbers being negatively correlated to the chlorate concentration. We purified many colonies onto YPD plates and re-tested them on chlorate medium to verify whether the acquisition of the $\mathrm{Clo}^{\mathrm{r}}$ trait was permanent. All colonies tested retained this trait after YPD cultivation. Two thousand $\mathrm{Clo}^{\mathrm{r}}$ colonies were identified and stored for further analyses.

\section{Identification of NR activity mutants}

Two hundred of the $\mathrm{Clo}^{\mathrm{r}}$ mutants were tested for growth on MA, MN1 and MN3 and 180 mutants were identified with $\mathrm{Nit}^{-} \mathrm{Nii}$ (nitrite) ${ }^{+}$phenotype. This phenotype suggested that, as expected from the selection procedure (chlorate plates with nitrite as sole nitrogen source), in these mutants only the first step of nitrate assimilation (nitrate reduction) is impaired. We tested the NR activity of 20 of these mutants after $3 \mathrm{~h}$ in nitrate medium and found strongly decreased NR activities in all of them (NR- phenotype). Most of these mutants have no NR activity, and the others show 10-100-fold reductions (Table 1). These data indicated that most, if not all, the $\mathrm{Nit}^{-} \mathrm{Nii}^{+}$mutants have structural or regulatory lesions which lead to reduction of NR activities.

\section{Genetic analyses}

Each of the $20 \mathrm{NR}^{-}$mutants (met6, $\mathrm{Nit}^{-}$) was crossed with strain L1 (leu1, $\mathrm{Nit}^{+}$) and diploids were selected onto MA plates. All resulting diploids showed chlorate sensitivity $\left(\mathrm{Clo}^{\mathrm{s}}\right)$ on $\mathrm{MC}$ plates, as well as good growth on nitrate medium $\left(\mathrm{Nit}^{+}\right)$. They were sporulated and random analyses of approximately 200 spore populations revealed a 1:1 ratio of $\mathrm{Nit}^{+}$and $\mathrm{Nit}^{-}$phenotypes from each population. Twenty-five $\mathrm{Nit}^{-}$spore products from each population were further examined. They revealed that in all cases the $\mathrm{Clo}^{\mathrm{r}}$, $\mathrm{Nit}^{-}$and $\mathrm{NR}^{-}$ phenotypes co-segregated. Taken together, these data indicated that the phenotype of each of the 20 mutants 
Table 2. Complementation matrix representing $41 \mathrm{Nit}^{-}$mutants of $H$. polymorpha crossed with 10 'tester' mutants in all pairwise combinations

+ , Crosses which grow on nitrate medium, indicating complementation; - , crosses which do not grow on nitrate medium, indicating non-complementation.

\begin{tabular}{|c|c|c|c|c|c|c|c|c|c|c|}
\hline \multirow{2}{*}{$\begin{array}{l}\mathrm{Nit}^{-} \\
\text {mutant }\end{array}$} & \multicolumn{10}{|c|}{ Tester mutant } \\
\hline & CP1 & CP2 & CP6 & CP7 & CP192 & CP193 & $\mathrm{CP3}$ & CP9 & CP10 & CP14 \\
\hline CP101 & - & + & + & + & + & + & + & + & + & + \\
\hline CP103 & + & + & + & - & + & + & + & + & + & + \\
\hline CP104 & - & + & + & + & + & + & + & + & + & + \\
\hline CP109 & - & + & + & + & + & + & + & + & + & + \\
\hline CP110 & + & + & - & + & + & + & + & + & + & + \\
\hline CP111 & + & + & - & + & + & + & + & + & + & + \\
\hline CP112 & + & + & + & - & + & + & + & + & + & + \\
\hline CP138 & - & + & + & + & + & + & + & + & + & + \\
\hline CP141 & + & + & + & - & + & + & + & + & + & + \\
\hline CP143 & + & + & + & - & + & + & + & + & + & + \\
\hline CP145 & - & + & + & + & + & + & + & + & + & + \\
\hline CP158 & - & + & + & + & + & + & + & + & + & + \\
\hline CP160 & - & + & + & + & + & + & + & + & + & + \\
\hline CP167 & + & + & + & + & - & + & + & + & + & + \\
\hline CP168 & + & + & + & + & - & + & + & + & + & + \\
\hline CP171 & + & + & + & + & - & + & + & + & + & + \\
\hline CP172 & + & + & + & + & - & + & + & + & + & + \\
\hline CP185 & + & - & + & + & + & + & + & + & + & + \\
\hline CP189 & + & + & + & - & + & + & + & + & + & + \\
\hline CP190 & + & - & + & + & + & + & + & + & + & + \\
\hline CP194 & + & + & - & + & + & + & + & + & + & + \\
\hline CP195 & + & + & + & - & + & + & + & + & + & + \\
\hline CP196 & + & - & + & + & + & + & + & + & + & + \\
\hline CP205 & + & + & + & - & + & + & + & + & + & + \\
\hline CP206 & + & + & - & + & + & + & + & + & + & + \\
\hline СР207 & - & + & + & + & + & + & + & + & + & + \\
\hline CР208 & - & + & + & + & + & + & + & + & + & + \\
\hline СР209 & + & + & + & - & + & + & + & + & + & + \\
\hline CP210 & + & + & + & - & + & + & + & + & + & + \\
\hline CР231 & + & + & + & - & + & + & + & + & + & + \\
\hline СР232 & - & + & + & + & + & + & + & + & + & + \\
\hline CР235 & - & + & + & + & + & + & + & + & + & + \\
\hline СР236 & + & + & + & - & + & + & + & + & + & + \\
\hline СР237 & + & + & + & + & - & + & + & + & + & + \\
\hline СР238 & + & + & + & - & + & + & + & + & + & + \\
\hline СР239 & + & + & + & - & + & + & + & + & + & + \\
\hline СР247 & - & + & + & + & + & + & + & + & + & + \\
\hline СР248 & + & + & + & - & + & + & + & + & + & + \\
\hline СР250 & + & + & + & - & + & + & + & + & + & + \\
\hline CP251 & + & + & - & + & + & + & + & + & + & + \\
\hline CP252 & + & + & + & - & + & + & + & + & + & + \\
\hline
\end{tabular}

was due to a single recessive mutation inherited in a Mendelian fashion.

Each of the 20 mutants was subjected to complementation analysis. Firstly, a set of leu1-marked derivatives of each $\mathrm{Nit}^{-}$mutant was obtained. Secondly, each mutant was crossed with each leu1 derivative and prototrophic diploids were selected onto minimal me- dium. Thirdly, diploid colonies were tested for complementation of $\mathrm{Nit}^{-}$mutations by their ability to grow on nitrate medium. This complementation analysis showed that the 20 mutations under study represented 10 complementation groups (Table 1). Finally, one 'tester' for each group was crossed with each of 41 additional $\mathrm{Nit}^{-}$mutants. The analysis of these crosses (Table 2) reveals that each mutant can be ascribed to one of the 
Table 3. Group distribution (1-10) of the 61 Nit- $^{-}$mutants analysed in this study

\begin{tabular}{|c|c|c|c|c|c|c|c|c|c|}
\hline 1 & 2 & 3 & 4 & 5 & 6 & 7 & 8 & 9 & 10 \\
\hline CP1 & $\mathrm{CP} 2$ & CP6 & CP7 & CP192 & CP193 & CP3 & CP9 & CP10 & CP14 \\
\hline $\mathrm{CP} 4$ & CP16 & CP5 & CP103 & CP167 & & & & & \\
\hline CP11 & СР222 & CP8 & CP112 & CP168 & & & & & \\
\hline CP12 & CP185 & CP15 & CP141 & CP171 & & & & & \\
\hline CP13 & CP190 & CP110 & CP143 & CP172 & & & & & \\
\hline CP221 & CP196 & CP111 & CP189 & CP237 & & & & & \\
\hline CP101 & & CP194 & CP195 & & & & & & \\
\hline CP104 & & CP206 & CP205 & & & & & & \\
\hline CP109 & & CP251 & СР209 & & & & & & \\
\hline CP138 & & & CP210 & & & & & & \\
\hline CP145 & & & CP231 & & & & & & \\
\hline CP158 & & & CP236 & & & & & & \\
\hline CP160 & & & CP238 & & & & & & \\
\hline CP207 & & & CP239 & & & & & & \\
\hline CP208 & & & CP248 & & & & & & \\
\hline CP232 & & & CP250 & & & & & & \\
\hline CP235 & & & CP252 & & & & & & \\
\hline CP247 & & & & & & & & & \\
\hline
\end{tabular}

previously defined groups. Table 3 summarizes the group distribution of the $61 \mathrm{Nit}^{-}$mutants analysed.

\section{Mutant growth on different nitrogen sources}

The growth capabilities of the $\mathrm{Nit}^{-}$mutants on different nitrogen sources (glutamate, aspartate, methylamine, hypoxanthine) were assayed by streaking one tester for each group on appropriate plates and incubating at $37^{\circ} \mathrm{C}$ for $5 \mathrm{~d}$. The results show that on all nitrogen sources, the testers grow as well as the control strain, indicating that the mutations under study affect specifically the nitrate pathway. All testers were also incubated on nitrate medium with the addition of sodium molybdate, but growth was never observed.

\section{DISCUSSION}

In $H$. polymorpha, NR activity is induced by nitrate, as long as ammonium or other reduced nitrogen sources are absent. These nitrogen sources repress NR activity. Loss of NR activity from nitrate-grown cells is stimulated by ammonium or other reduced nitrogen sources, whether or not nitrate is present. Although the dynamics of repression are different for the different compounds, NR activity is never induced in the absence of nitrate. Taken together, these results indicate that in $H$. polymorpha the synthesis of NR is subjected to dual control: repression mechanisms elicited by ammonium (and other reduced nitrogen compounds) and induction phenomena stimulated by nitrate (and to a lesser extent by nitrite). These data mirror the RNA blot analysis of the H. polymorpha YNR1 gene (Avila et al., 1995). The repressing stimuli overcome the inducing stimuli, i.e. when presented with nitrate and ammonium $H$. polymorpha utilizes ammonium in preference to nitrate. These indications suggest that in this respect $H$. polymorpha NCYC 495 is similar to Aspergillus nidulans (Cove, 1979), Neurospora crassa (Garrett \& Amy, 1978), Hansenula wingei ATCC 28162 (Jones et al., 1987), Sporobolomyces roseus (Ali \& Hipkin, 1985) and $H$. polymorpha CBS 4732 (González \& Siverio, 1992) but differs from $H$. wingei CBS 2432 (González \& Siverio, 1992), Candida nitratophila (Cannons et al., 1986) and Hansenula anomala (González \& Siverio, 1992) since in these yeasts ammonium + nitrate cultures result in measurable NR activities (e.g. in C. nitratophila, $25 \%$ of the fully induced activity of nitrategrown cells; Cannons et al., 1986) and in the concomitant utilization of the two nitrogen sources. It is interesting to note that increases but not decreases in NR activity were dependent on protein synthesis. These observations can be explained by assuming the coexistence of two modes of control. A long-term, coarse mechanism, dependent on protein synthesis, could regulate the synthesis of $N R$ in response to the nitrogen source (interestingly, in two other Hansenula species, the appearance and disappearance of NR correlates well with the syntheses and losses of NR protein; González \& Siverio, 1992). This mechanism is likely to act at the transcriptional level, as indicated by the fact that the NR-coding gene of $H$. polymorpha is transcriptionally regulated (Avila et al., 1995). A short-term, fine mechanism, independent of protein synthesis, could account for the observed NR activity losses in the presence of cycloheximide. This mechanism could rapidly inhibit nitrate assimilation in response to the addition of ammonium by acting early in the pathway, i.e. at the uptake and/or NR level. Although the nature of this action is obscure, reversible or irreversible inactivation 
of NR is a likely mechanism; it is noteworthy that in vivo inactivation of NR in another Hansenula species has been reported (Minagawa \& Yoshimoto, 1984).

H. polymorpha differs from S. roseus and C. nitratophila in that removal of ammonium from ammonium-grown cultures does not bring about 'gratuitous' NR activities (Ali \& Hipkin, 1985; Cannons et al., 1986). Thus in this yeast, NR activity does not seem to be strongly regulated by derepression. However, following growth on nitrate, NR activity is present in nitrogen-starved cells and may be sustained for at least $6 \mathrm{~h}$ in the absence of nitrate, as long as protein synthesis is active. Thus cycloheximide seems to inhibit the synthesis of a system involved in the NR inactivation (or perhaps in weak NR derepression). If protein synthesis is inhibited by cycloheximide, the presence of nitrate results in the maintenance of the existing NR levels, suggesting that nitrate plays a role in protecting NR from the supposed inactivation mechanisms.

Mutants defective in NR activity were isolated following chlorate selection procedures. We observed that wildtype $H$. polymorpha is sensitive to high levels of potassium chlorate $(0.3 \mathrm{M}$ and higher) on medium allowing NR expression. After optimizing the procedure, we were able to isolate $\mathrm{Clo}^{\mathrm{r}}$ mutants, many of which were also $\mathrm{Nit}^{-}$. This fact indicated that these mutants could be isolated with a simple positive selection procedure. During this study, we confined the genetic dissection of the nitrate metabolism to the NR activity, and therefore concentrated on $61 \mathrm{Nit}^{-}$mutants. These mutants, shown to be due to a mutation in a single recessive gene, were grouped in 10 complementation classes, revealing a complex set of genes involved in the NR activity of $H$. polymorpha. The high number of classes defined indicates that the procedure adopted is very effective in identifying the diverse genes of this set. It is likely that both structural and regulatory lesions are present in our collection. By analogy with other organisms, it is possible to speculate that, apart from the NR structural gene (YNR1; Avila et al., 1995), one or more nitrate transporters can be mutated. In this case, we must assume that lack of uptake would impede NR induction (it is noteworthy that recently the YNT1 gene encoding a nitrate transporter of $H$. polymorpha has been cloned and its disruption has been shown to cause inability to grow in nitrate and, to a certain extent, reductions in NR activity; Pérez et al., 1997). Additionally, the Mo prosthetic group biosynthetic genes as well as regulatory elements, if mutated, may lead to the $\mathrm{NR}^{-}$phenotype. Some of these can be NR-specific; others can be involved in the regulation of more than one pathway. To further our understanding of these mutants, we tested them on a number of nitrogen sources and found that none of the mutants show reduced capabilities of utilization of diverse nitrogen sources alternative to ammonium. Thus it is plausible that in these mutants, lesions have occurred to genes playing major roles in the regulation of nitrate metabolism but not in the regulation of other nitrogen utilization pathways. Furthermore, none of the mutants tested showed reduced growth on hypoxanthine medium and in none of these mutants was it possible to rescue the $\mathrm{Nit}^{-}$phenotype in media with high Mo concentration, thus excluding a possible role of these genes in the biosynthetic pathway leading to the molybdopterin prosthetic group, since this prosthetic group is shared with hypoxanthine-xanthine dehydrogenase, involved in hypoxanthine utilization.

Our large collection of $H$. polymorpha $\mathrm{Nit}^{-}$mutants (including some with altered NiR activity not described in this report), together with the availability of efficient transformation systems and replicating vectors for this yeast, will allow the cloning of $H$. polymorpha NIT genes by functional complementation. The predicted amino acid sequences of NIT products, along with biochemical and physiological information obtained from the mutants, should provide useful insight into the role of specific NIT products in nitrate assimilation. Gene isolation experiments aimed at identifying these structural and regulatory products are under way, together with genetic work aimed at characterizing more $\mathrm{Nit}^{-}$mutants.

\section{REFERENCES}

Áberg, B. (1947). On the mechanism of the toxic action of chlorates and some related substances upon young wheat plants. K Lantbrukshögsk Ann 15, 37-107.

Ali, A. H. \& Hipkin, C. R. (1985). Nitrate assimilation in the basidiomycete yeast Sporobolomyces roseus. J Gen Microbiol 131, 1867-1874.

Avila, J., Pérez, M. D., Brito, N., González, C. \& Siverio, J. M. (1995). Cloning and disruption of the YNR1 gene encoding the nitrate reductase apoenzyme of the yeast Hansenula polymorpha. FEBS Lett 366, 137-142.

Barnett, J. A., Payne, R. W. \& Yarrow, D. (1984). Yeasts: Characteristics and Identification, 2nd edn. Cambridge: Cambridge University Press.

Berardi, E. (1997). Genetics and molecular biology of methylotrophic yeasts. In Yeasts in Natural and Artificial Habitats, pp. 264-294. Edited by J. F. T. Spencer \& D. M. Spencer. Berlin: Springer.

Brito, N., Avila, J. M., Pérez, D., González, C. \& Siverio, J. M. (1996). The genes YNI1 and YNR1, encoding nitrite reductase and nitrate reductase respectively in the yeast Hansenula polymorpha, are clustered and co-ordinately regulated. Biochem J 317, 89-95.

Bruinenberg, P. M., van Dijken, J. P. \& Scheffers, W. A. (1983). An enzymic analysis of NADPH production and consumption in Candida utilis. J Gen Microbiol 129, 965-971.

Campbell, W. H. \& Kinghorn, J. R. (1990). Functional domains of assimilatory nitrate reductases and nitrite reductases. $J$ Biochem Sci 15, 315-319.

Cannons, A., Ali, A. H. \& Hipkin, C. R. (1986). Regulation of nitrate reductase synthesis in the yeast Candida nitratophila. $J$ Gen Microbiol 132, 2005-2011.

Cove, D. J. (1976). Chlorate toxicity in Aspergillus nidulans: the selection and characterization of chlorate resistant mutants. Heredity 36, 191-203.

Cove, D. J. (1979). Genetic studies of nitrate assimilation in Aspergillus nidulans. Biol Rev Camb Philos Soc 54, 291-327. 
Faber, K. N., Westra, S., Waterham, H. R., Keizer-Gunnink, I., Harder, W., Ab, G. \& Veenhuis, M. (1996). Foreign gene expression in Hansenula polymorpha. A system for the synthesis of small functional peptides. Appl Microbiol Biotechnol 45, 72-79.

Garrett, R. N. \& Amy, N. K. (1978). Nitrate assimilation in fungi. Adv Microb Physiol 18, 1-65.

Gleeson, M. A. \& Sudbery, P. E. (1988). Genetic analysis in the methylotrophic yeast Hansenula polymorpha. Yeast 4, 293-303.

González, C. \& Siverio, J. M. (1992). Effect of nitrogen source on the levels of nitrate reductase in the yeast Hansenula anomala. $J$ Gen Microbiol 138, 1445-1451.

Guerrero, M. G., Vega, J. M. \& Losada, M. (1981). The assimilatory nitrate-reducing system and its regulation. Annu Rev Plant Physiol 32, 169-204.

Hipkin, C. R. (1989). Nitrate assimilation in yeasts. In Molecular and Genetic Aspects of Nitrate Assimilation, pp. 51-68. Edited by J. L. Wray \& J. R. Kinghorn. Oxford: Oxford Science Publications.

Jones, C. P., Wray, J. L. \& Kinghorn, J. R. (1987). The role of nitrogen sources in the regulation of nitrate reductase and nitrite reductase levels in the yeast Hansenula wingei. J Gen Microbiol 133, 2767-2772.
Minagawa, N. \& Yoshimoto, A. (1984). The in vivo inactive nitrate reductase from Hansenula anomala. Agric Biol Chem 48, 1907-1909.

Pérez, M. D., González, C., Avila, J., Brito, N. \& Siverio, J. M. (1997). The YNT1 gene encoding the nitrate transporter in the yeast Hansenula polymorpha is clustered with genes YNI1 and YNR1 encoding nitrite reductase and nitrate reductase, and its disruption causes inability to grow in nitrate. Biochem $J$ 321, 397-403.

Solomonson, L. P. \& Barber, M. J. (1990). Assimilatory nitrate reductase: functional properties and regulation. Annu Rev Plant Physiol Plant Mol Biol 41, 225-253.

Veenhuis, M. (1992). Peroxisome biogenesis and function in Hansenula polymorpha. Cell Biochem Funct 10, 175-184.

Waterham, H. R. \& Cregg, J. M. (1997). Peroxisome biogenesis. BioEssays 19, 57-66.

Wray, J. L. \& Kinghorn, J. R. (editors) (1989). Molecular and Genetic Aspects of Nitrate Assimilation. Oxford: Oxford Science Publications.

Received 28 January 1998; revised 9 March 1998; accepted 7 April 1998. 